\title{
Investigations on Effect of Notch on Performance Evaluation of Cantilever Beams
}

\author{
S. H. Gawande and R. R. More \\ Department of Mechanical Engineering, M. E.Society's College of Engineering, Pune, Maharashtra, India.
}

(Received 17 February 2015; accepted 7 April 2015)

It is required that any structure must work properly during its service life time. However, due to the internal damage of structures, there may be a chance of breakdown. Therefore, structures require regular costly inspection. During the last few decades, vibration-based fault detection methods are mostly used due to their simplicity for implementation. During operation, all structures are subjected to degenerative effects that may cause initiation of structural fault such as cracks or notch that lead to the disastrous failure or collapse of the structure. It is seen that as crack or notch starts generating, there is a change in natural frequencies. This research work focuses on the examination of these changes, which is useful for identification of notch position. In this paper, the detailed analysis of cantilever beam with and without notch has been done using finite element method with the help of ANSYS and using modern national instruments LabVIEW software. This method provides the information regarding the detection, location, and characterization of the damage in the structure. This paper includes the study of dynamic properties of cantilever beams subjected to free vibration under the influence of notch at different positions along the length.

\section{INTRODUCTION}

Beams are very important elements in many mechanical and structural engineering applications. They are commonly used to create a foundation or internal support for a larger structure, such as a building or a bridge. There have been several recent instances of structures, such as building and bridges, cracking, failing, or collapsing for example Tacoma Bridge in London ${ }^{1}$ as shown in Fig. 1. Therefore, it is necessary to study dynamic characteristics of beams such as natural frequencies and mode shape during existence of crack subjected to the vibration. This dynamic behaviour of a structure is affected due to the presence of a crack as the stiffness of that structural element is altered.

Numerous studies have been carried out on conventional (dye penetrant, magnetic particle induction, ultrasonic etc.) and modern approaches to non-destructive testing and evaluation. The conventional methods have been well developed, implemented in widely marketed equipment, and accepted by industry and regulatory agencies as practically applicable nondestructive valuation (NDE) methods. The modern NDE methods are still under development, implemented in a limited manner in some equipment, and not fully accepted by the industry and regulatory agencies as practicably applicable NDE methods. One of these modern methods is the vibration-based inspection methodology. Vibrations are the inherent properties of the physical science applicable to all structures subjected to static or dynamic loads. All structures again due to their rigid nature develop some irregularities in their life span, which leads to the development of cracks. The problem on crack is the basic problem of science of resistance of materials. Considering the crack as a significant form of such damage, its

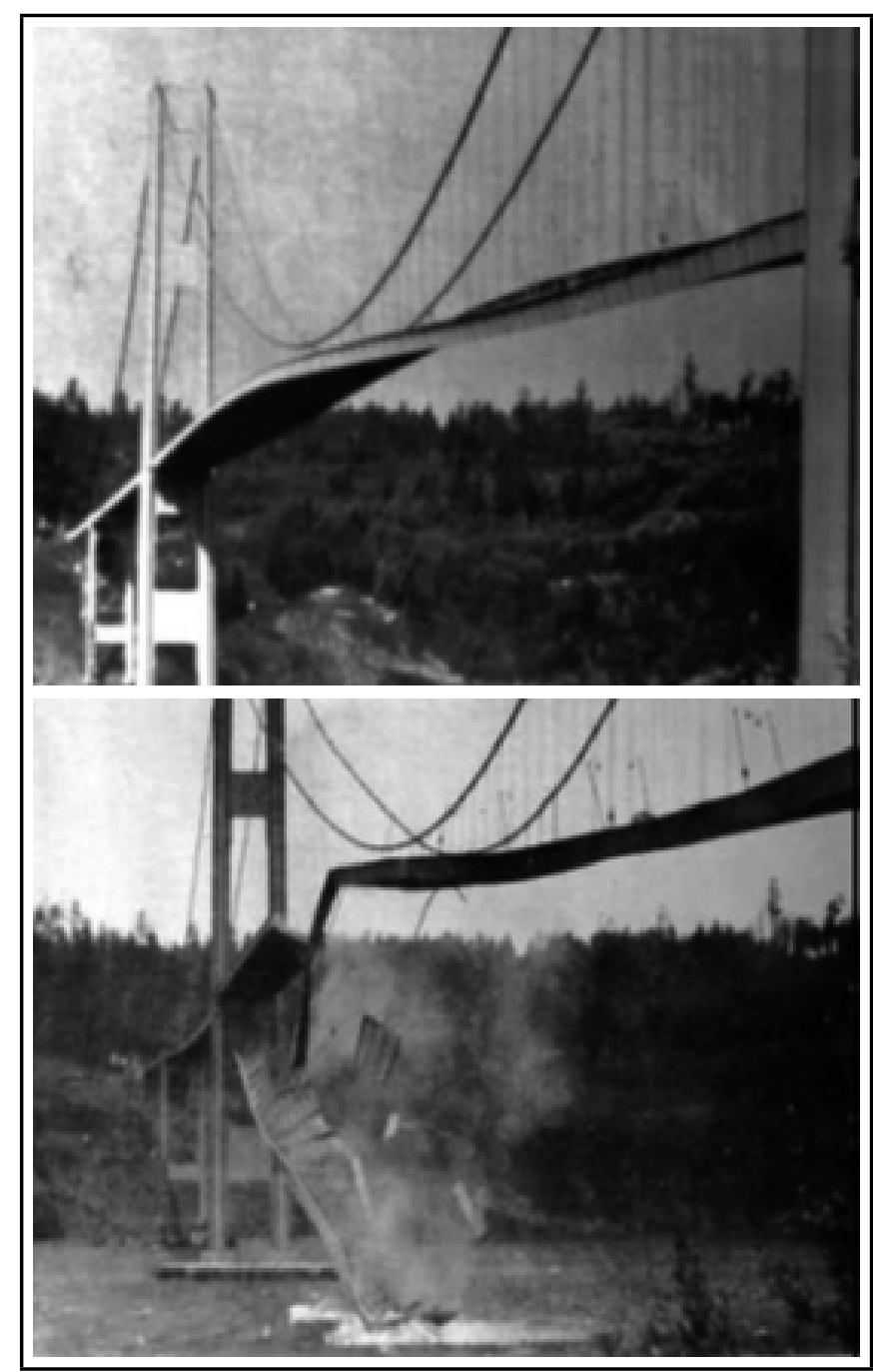

Figure 1. Tacoma Narrows Bridge Disaster. 
modelling is an important step in studying the behaviour of damaged structures. Knowing the effect of crack on stiffness, the beam or shaft can be modelled using either Euler-Bernoulli or Timoshenko beam theories. The beam boundary conditions are used along with the crack compatibility relations to derive the characteristic equation relating the natural frequency, the crack depth, and location with the other beam properties. Researches based on structural health monitoring for crack detection deal with change in natural frequencies and mode shapes of the beam have been previously conducted.

\section{LITERATURE REVIEW}

Sethi, et al. ${ }^{2}$ have analysed the vibration behaviour of cantilever beam using Ansys software by generating cracks at different location for various depths on cantilever beam. Owolabi et al. ${ }^{3}$ considered two beams namely cantilever beam and fixed beam for investigation, after that they initiated cracks at seven different locations from one end to the other end (along the length of the beam), with different range of crack depth ratio. They measured acceleration frequency responses at seven different points on each beam. From the experimental work, they observed that the crack can be detected by analysing change in the natural frequency and amplitudes of frequency response function. Agarwalla et al. ${ }^{4}$ have experimentally analysed effect of an open crack on the modal parameters of the cantilever beam subjected to free vibrations and compared with results obtained from the numerical method. Nahy and Jabbari ${ }^{5}$ have established an analytical as well as experimental approach for crack detection in cantilever beams by vibration analysis. An experimental setup was designed in which a cracked cantilever beam is excited by a hammer and the response is obtained by an accelerometer attached to the beam. To identify the crack, contours of the normalized frequency in terms of the normalized crack depth and location are plotted. Georgiades et al. ${ }^{6}$ have performed a theoretical linear modal analysis of EulerBernoulli L-shaped beam structure by solving two sets of coupled partial differential equations of motion. Huang and Zhang ${ }^{7}$ have illustrated the mechanism of modal coupling in cantilever beam plate flutter using the full Theodorsen airfoil theory within the linear framework. An accurate, pseudo-spectral method is employed to calculate the fluid loading, and the eigen value problem is solved numerically using Galerekins method. Jassim et al. ${ }^{8}$ determined analytical and experimental investigations on the effects of a crack on the cantilever steel beam with circular cross section. They determined the extent of the damage magnitude and the location of the cantilever beams. They observed that monitoring the change of the natural frequency is a feasible and viable tool to indicate the damage occurrence and magnitude. Nguyen ${ }^{9}$ has analysed mode shapes of a cracked beam with a rectangular cross section beam using finite element method (FEM). He determined that the existence of the crack can be detected based on the mode shapes, when the mode shapes are space curves. Moreover, when there is a crack, the mode shapes have distortions or sharp changes at the crack position. Thus, the position of the crack can be determined as a position at which the mode shapes exhibit such distortions or sharp changes. Khiem and Toan ${ }^{10}$ have proposed a method for calculating the natural frequencies of a multiple cracked beam and detecting unknown number of multiple cracks from the measured natural frequencies. Thalapil and Maiti ${ }^{11}$ have developed an analytical method to address both forward problem of determination of natural frequencies knowing the beam and crack geometry details as well as inverse problem of detection of crack with the knowledge of changes in the beam natural frequencies. Both long (EulerBernoulli) and short (Timoshenko) beams have been examined numerically. Nejad et al. ${ }^{12}$ have given an analytical estimation based on the Rayleigh's method, extended for a beam having one or two cracks to find natural frequencies and mode shapes in order to overcome weakness of solving eigen value problem. They developed an algebraic equation that must be solved numerically, and then coefficients of trigonometric and hyperbolic terms in mode shapes are found using matrices obtained from compatibility conditions at each point of cracks and boundary conditions. The advantage of analytical estimation based on the Rayleigh's method over the eigen analysis method is that the Rayleigh method obtains explicit expression for both natural frequencies and mode shapes in which the effect of parameters such as crack size and location on natural frequencies and mode shapes can be investigated analytically. Singh and Tiwari ${ }^{13}$ have presented experimental verification of an algorithm for detection and localization of multiple cracks in a simple shaft system. The algorithm is based on detection of slope discontinuity caused by the cracks. Jena et al. ${ }^{14}$ have given the fault detection of Multi cracked slender Euler Bernoulli beams through the knowledge of changes in the natural frequencies and their measurements. The method is based on the approach of modelling a crack by rotational spring. Barad et al. ${ }^{15}$ have presented detection of the crack presence on the surface of beam-type structural element using natural frequencies. Sutar ${ }^{16}$ described the finite element analysis of a cracked cantilever beam and analysed the relation between the modal natural frequencies with crack depth and modal natural frequencies with crack location. Further, he analysed the relation among the crack depth, crack location, and natural frequency. Prasad et al. ${ }^{17}$ found out the effect of location of crack from free end to fixed end on crack growth rate along vibrating cantilever beam. Saavedra and cuitino ${ }^{18}$ presented a theoretical and experimental dynamic behaviour of different multi-beam systems containing transverse crack. Their proposed method is used to evaluate the dynamic analysis response of cracked free-free beam and a U-frame when harmonic force is applied. Vigneshwaran and Behera ${ }^{19}$ studied the dynamic characteristics of a beam with multiple breathing cracks. They developed a systematic approach that has been adopted to develop theoretical expressions for evaluation of natural frequencies and mode shapes. Saptarshi and Ramanjaneyelu presented ${ }^{20}$ a methodology for detection and quantification of structural damage using modal information obtained from transfer matrix technique. Dawari and Vesmawala ${ }^{21}$ have 


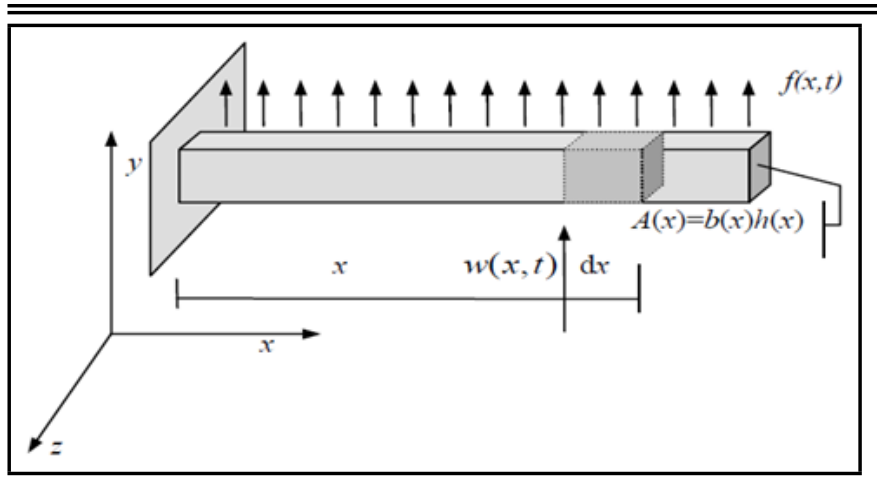

Figure 2. Cantilever beam.

detected and located the damage in beam models with different boundary condition by using modal based damage detection method.

In this era, the world now has become unstable because of many factors. From the case as explained in early part of the introduction, failing or collapsing of buildings and bridges (for example, Tacoma Bridge in London) had a lot of scope for study and investigation. Again, from literature review it is seen that a lot of work is performed on detection of crack by using natural frequency and amplitudes of frequency response functions for simply supported structures and cantilever beams. However, very less amount of research work is reported on cantilever beams with notch. Hence, from these cases, ideas come in our mind to make an analysis of one of the structure like beam to understand their behaviour to enhance the performance by studying dynamic properties of different cantilever beams subjected to free vibration under the influence of notch at different positions along the length to reduce failure. This paper focuses on the investigation of cantilever beams behaviour with notch at different locations.

\section{THEORETICAL ANALYSIS}

Figure 2 shows cantilever beam having cross-sectional area 'A' with width ' $b$ ' and depth ' $h$ '. For analysis purpose, infinitesimal element is considered at a distance of ' $x$ ' along its length from fixed end. This element has length ' $d x$ '. The crosssectional area of this element is represented as:

$$
A(x)=b(x) h(x) .
$$

Following boundary conditions are used to perform further analysis of the cantilever beam.

At fixed end, i.e. at $x=0$, displacement and slope are zero,

$$
\begin{aligned}
\text { i.e. displacement, } & W(0, t)=0 ; \\
\text { slope }, & W_{1 x}(0, t)=0 .
\end{aligned}
$$

At free end, i.e. at $x=l$, bending moment and shear forces are zero,

$$
\begin{aligned}
\text { i.e. bending moment } & E I W_{1 x x}(l, t)=0 ; \\
\text { shear force, } & E I W_{1 x x x}(l, t)=0 .
\end{aligned}
$$

The equation of motion for Euler-Bernoulli beam is given by,

$$
\rho A \frac{d^{2} W}{d t^{2}}+E I \frac{d^{4} W}{d x^{4}}=0
$$

We consider,

$$
W(x, t)=e^{i \omega t} W(x) .
$$

The differential equation of eigenvalue problem is,

$$
-\omega^{2} W \rho A+E I \frac{d^{4} W}{d x^{4}}=0 .
$$

By using with boundary conditions as,

$$
W(0)=0, W^{1}(0)=0, W^{l l}(l)=0, W^{l l l}(l)=0 .
$$

So, the general solution is given by,

$W_{(x)}=B_{1} \cosh \beta x+B_{2} \sin h \beta x+B_{3} \cos \beta x+B_{4} \sin \beta x$.

By using above four boundary conditions, following condition is obtained,

$$
\left[\begin{array}{cccc}
1 & 0 & 1 & 0 \\
0 & 1 & 0 & 1 \\
\cos h \beta l & \sin h \beta l & -\cos \beta l & -\sin \beta x \\
\sin h \beta l & \cos h \beta l & \sin \beta x & \cos \beta l
\end{array}\right]\left(\begin{array}{l}
B 1 \\
B 2 \\
B 3 \\
B 4
\end{array}\right)=0 .
$$

For non-trival solution of $B_{1}, B_{2}, B_{3}, B_{4}$, determinant of this matrix (A) must vanish. Therefore, the determinant of the matrix (A) is,

$$
\cos \beta l \cosh \beta l+1=0 .
$$

This is the characteristic equation for cantilever beam.

$$
\cos \beta l=\frac{-1}{\cosh \beta l}
$$

so,

$$
\cos z=\frac{-1}{\cosh z}
$$

For higher modes $\cos \beta l \cong 0$. We can write,

$$
\beta_{n} l=\frac{(2 n-1) \pi}{2}+e_{n}, \quad \text { where } n=1,2.3 \ldots ;
$$

where $e_{n}$ is some error. When we calculate en for solution of characteristic equation, it will deviates by the amount as;

$$
\begin{gathered}
e_{1}=0.3042 \text { for first mode; } \\
e_{2}=-0.018 \text { for second mode; } \\
e_{3}=0.001 \text { for third mode. }
\end{gathered}
$$

Then, as we know

$$
\beta_{n}{ }^{2}=\omega_{n} \sqrt{\frac{A \rho}{E I}}
$$

This implies that,

$$
\omega_{n}=\left[\frac{(2 n-1) \pi}{2}+e_{n}\right]^{2} \frac{1}{l^{2}} \sqrt{\frac{E I}{A \rho}} .
$$

Equation (6) is used to calculate the circular natural frequency for cantilever beams in $\mathrm{rad} / \mathrm{sec}$. This value of frequency is converted into $\mathrm{Hz}$, by dividing $\omega_{n}$ by $2 \pi$. 


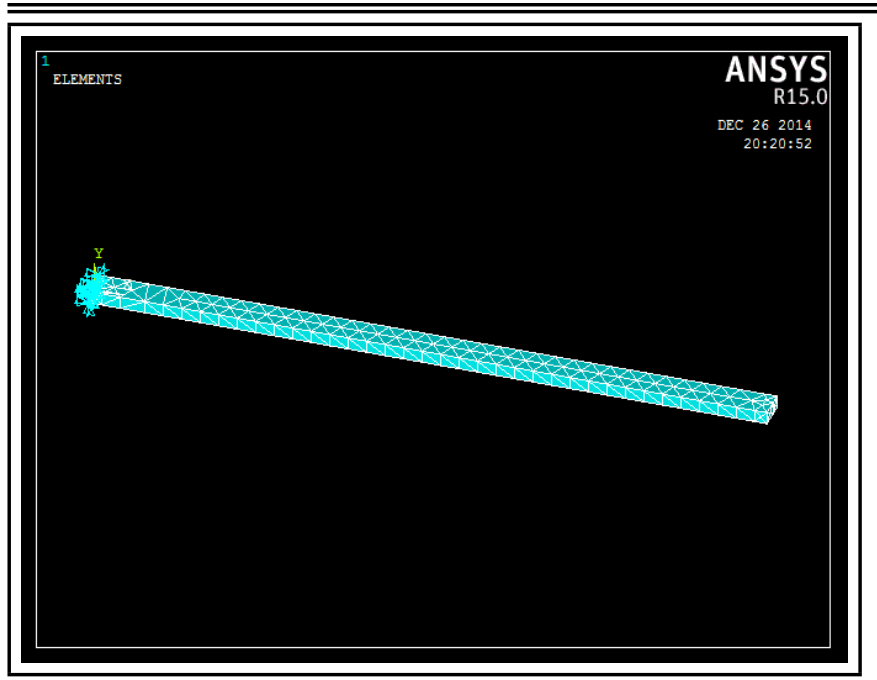

Figure 3. Meshed cantilever beam without notch.

\section{NUMERICAL ANALYSIS}

The numerical analysis is carried out for the cantilever beam to find the natural frequencies of transverse vibration. The cantilever beam made of aluminium $\left(E=70 \times 10^{9} \mathrm{~N} / \mathrm{m}^{2}\right.$, $\left.\rho=2700 \mathrm{~kg} / \mathrm{m}^{3}, v=0.35\right)$ is selected with dimensions as length $=550 \mathrm{~mm}$, width $=25 \mathrm{~mm}$, and height $=10 \mathrm{~mm}$. The modal analysis of aluminium cantilever beam has been done using Ansys software of version 14.5. In order to perform finite element analysis, creation of solid model of cantilever beam is important. Hence, cantilever beam is first modelled in PRO/E WILDFIRE, which is an excellent CAD software; it makes modelling easy and user friendly. Then the solid model is transferred in IGES format and exported into the Analysis software ANSYS 14.5. After that the cantilever beam is analysed in three steps. First is preprocessing which involves modelling, geometric clean up, element property definition, and meshing. Next step includes solution of the problem, which involves imposing boundary conditions on the model, and then the solution is tested. Figure 3 shows a meshed cantilever beam without notch. The next step in sequence is post processing, which involves analysing the natural frequency for different mode of vibrations.

\section{EXPERIMENTAL ANALYSIS}

In order to study the effect of notch on cantilever beams, the required experimental setup as shown in Fig. 4 is developed. Experimental setup includes instruments like data acquisition hardware (of specifications as shown in Table 1), accelerometer (of specifications as shown in Table 2), impact hammer (of specifications as shown in Table 3), a loaded personal computer (pc) or laptop, test-specimen, power supply for the pc and vibration analyser, connecting cables for the impact hammer, and accelerometer. The experimental analysis is carried out for the cantilever beams to find the natural frequencies of transverse vibration. The cantilever beam made of aluminium $\left(E=70 \times 10^{9} \mathrm{~N} / \mathrm{m}^{2}, \rho=2700 \mathrm{~kg} / \mathrm{m}^{3}, v=0.35\right)$ is selected with dimensions as length $=550 \mathrm{~mm}$, width $=25 \mathrm{~mm}$, height
Table 1. Specifications of the data acquisition system.

\begin{tabular}{|c|l|l|}
\hline Sr. No. & \multicolumn{1}{|c|}{ Parameter } & \multicolumn{1}{c|}{ Specification } \\
\hline 1. & Brand Make & National Instruments \\
\hline 2. & Number of channel & 4 \\
\hline 3. & Maximum sampling & $51.2 \mathrm{kS} / \mathrm{s}$ per channel \\
\hline 4. & Voltage input & $5 \mathrm{~V}$ \\
\hline 5. & Dynamic range & $102 \mathrm{DB}$ \\
\hline
\end{tabular}

Table 2. Specifications of the accelerometer.

\begin{tabular}{|c|l|l|}
\hline Sr. No. & \multicolumn{1}{|c|}{ Parameter } & \multicolumn{1}{|c|}{ Specification } \\
\hline 1. & Brand Make & National Instruments \\
\hline 2. & Model no. & PCB $352 \mathrm{C} 33$ \\
\hline 3. & Voltage sensitivity & $100 \mathrm{mv} / \mathrm{g}$ \\
\hline 4. & Frequency range & 0.3 to $12000 \mathrm{~Hz}$ \\
\hline 5. & Electrical connector & Type/location $5-44$ coaxial/side \\
\hline
\end{tabular}

Table 3. Specifications of the hammer.

\begin{tabular}{|c|l|l|}
\hline Sr. No. & \multicolumn{1}{|c|}{ Parameter } & \multicolumn{1}{c|}{ Specification } \\
\hline 1. & Brand Make & National Instruments \\
\hline 2. & Model no. & PCB086C03 \\
\hline 3. & Voltage range & $10 \mathrm{DB}$ \\
\hline 4. & Sensitivity element & Material/type quartz/Epoxy \\
\hline 5. & Electrical connector & type/location BNC/Bottom of handle \\
\hline
\end{tabular}

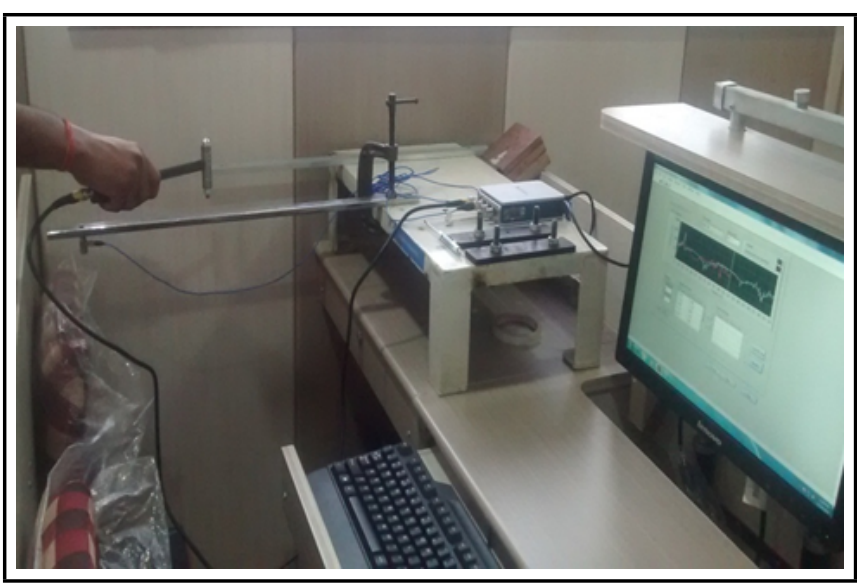

Figure 4. Experimental setuph.

$=10 \mathrm{~mm}$. The following procedure is followed to perform experiments.

\subsection{Experimental Procedure}

1. Prepare the cantilever beam: Measure the length on the fixture that holds the aluminium beam and leave a margin of that length on the aluminium beam. Fix the accelerometer to the aluminium beam at one node but on the face of the beam opposite to the markings. Ensure that face of beam with markings and node numbers up, fix the beam into the slot on the fixture so that a cantilever beam is formed.

2. Connect the wires and cables: Make connections of the data acquisition hardware, pc or laptop, accelerometer, and the impact hammer as given in the manuals. 
3. Switch on the power supply: Open the software of vibration analysis and experimental modal analysis installed on the pc/laptop. Provide the necessary inputs and make necessary settings in the software. Ensure that there is proper supply and communication between the devices connected.

4. Next provide impact by the impact hammer on the nodes marked on the cantilever beam one by one. Impact should be generally given on nodes. Accelerometer is connected at one node. Signals from the impact hammer and the accelerometer will be received by the data acquisition hardware/vibration analyser for each impact provided one by one and will be compared and analysed by the software. Then, the curve known as frequency response function (FRF) (as shown in Fig. 5) will be generated by the software, which is used to find the natural frequencies of the cantilever beam.

5. Then put the required number of nodes in the requisite frequency range, so that at each peak we will get a corresponding natural frequency.

6. Now determine mode shapes for each natural frequency (as shown in Fig. 6).

\subsection{FRF Output Screen on LabVIEW Software}

Figure 5 shows regular output of FRF of cantilever beam obtained by using NI LabVIEW software by performing exhaustive experiment on cantilever beam with no notch/crack using modal analysis. To perform modal analysis, six nodes are selected as shown in 3D mode structure window of Fig. 5. The number of nodes can be increased or decreased as per the requirement. Each node was tense by using hammer, which was taken as input to the considered specimen; it must be a single pick. Each node gives its corresponding FRF magnitude and acceleration. Acceleration is nothing but the output in terms of acceleration of cantilever beam that must be logarithmic decrement. Figure 5 particularly shows that the third node, which has been plugged using hammer, gives the corresponding FRF magnitude versus frequency and acceleration versus time graph. Input given to the third node is shown in Fig. 5 in terms of hammer versus time window and output in terms of acceleration versus time window, which is nothing but logarithmic decrement. Similar procedure was repeated for other nodes.

\subsection{Natural Frequency for Different Modes using LabVIEW}

Figure 6 shows the regular plot of peak natural frequency of cantilever beam with no notch for the corresponding mode obtained by using LabVIEW. In Fig. 6, the different picks obtained within a specified limit are nothing but the modes of vibration from the different number of modes corresponding to their natural frequencies. Figure 6 shows the average FRF
Table 4. Theoretical and experimental natural frequency of aluminium beam.

\begin{tabular}{|c|c|c|c|}
\hline $\begin{array}{c}\text { Mode } \\
\text { no. }\end{array}$ & $\begin{array}{c}\text { Theoretical } \\
\text { natural frequency } \\
(\mathrm{Hz})\end{array}$ & $\begin{array}{c}\text { Numerical natural } \\
\text { frequency } \\
(\mathrm{Hz})\end{array}$ & $\begin{array}{c}\text { Experimental } \\
\text { natural frequency } \\
(\mathrm{Hz})\end{array}$ \\
\hline 1 & 15.0891 & 16.824 & 14.575 \\
\hline 2 & 29.5676 & 33.465 & 30.005 \\
\hline 3 & 48.8771 & 63.669 & 62.436 \\
\hline 4 & 73.013 & $73 . .384$ & 87.288 \\
\hline 5 & 101.9781 & 105.08 & 115.965 \\
\hline 6 & 135.7698 & 141.24 & 128.144 \\
\hline
\end{tabular}

of six nodes. To get the FRF, first click on load FRF data as shown in Fig. 6 and call the file which has been saved. The graph highlighted in the red colour as shown in Fig. 6 is nothing but FRF graph and each pick of the graph gives the corresponding natural frequency. We can vary the range of natural frequency by moving the vertical lines shown in yellow colour. One can increase or decrease the natural frequency by changing the mode number, which is given in setting column.

\section{RESULTS AND DISCUSSION}

In order to comprehend the effect of notch on natural frequency, numbers of trials are conducted on cantilever beam for without notch \& different positions of notch.

\subsection{Natural Frequency for Cantilever Beam Without Notch}

Table 4 shows the theoretical, numerical, and experimental natural frequency of aluminium beam. Theoretical natural frequency of cantilever beam is calculated using Eq. (6) and experimental natural frequency is calculated using LabVIEW software. Fig. 7 shows the relation obtained for the natural frequency by the theoretical, numerical, and experimental approach. From Fig. 7, it is found that the theoretical and experimental natural frequencies of the aluminium beam are slightly deviating by $14 \mathrm{~Hz}, 10 \mathrm{~Hz}, 12 \mathrm{~Hz}$ (approx.) for the third, fourth, and fifth modes, respectively.

\subsection{Effect on Natural Frequencies of Cantilever Beam under the Influence of Notch}

The three natural frequencies i.e. first, second, and third are determined by the numerical method (FEM) using ANSYS version 14.5. First, the aluminium cantilever beam of the dimensions $0.55 \mathrm{~m} \times 0.025 \mathrm{~m} 0 \times 0.010 \mathrm{~m}$ is being modelled with ' $\mathrm{V}$ ' notch (depth $4.3 \mathrm{~mm}$, width $5 \mathrm{~mm}$ ) at two different positions. By modal analysis, three natural frequencies are obtained. These natural frequencies are compared with natural frequencies obtained by NI LabVIEW. Figure 8 shows solid model of cantilever beam with ' $\mathrm{V}$ ' notch. The position of notch is selected as $137.5 \mathrm{~mm}$ from free end of the beam and midpoint of the beam (i.e. $275 \mathrm{~mm}$ from free or fixed end) as shown in Fig. 8 (a \& b). 


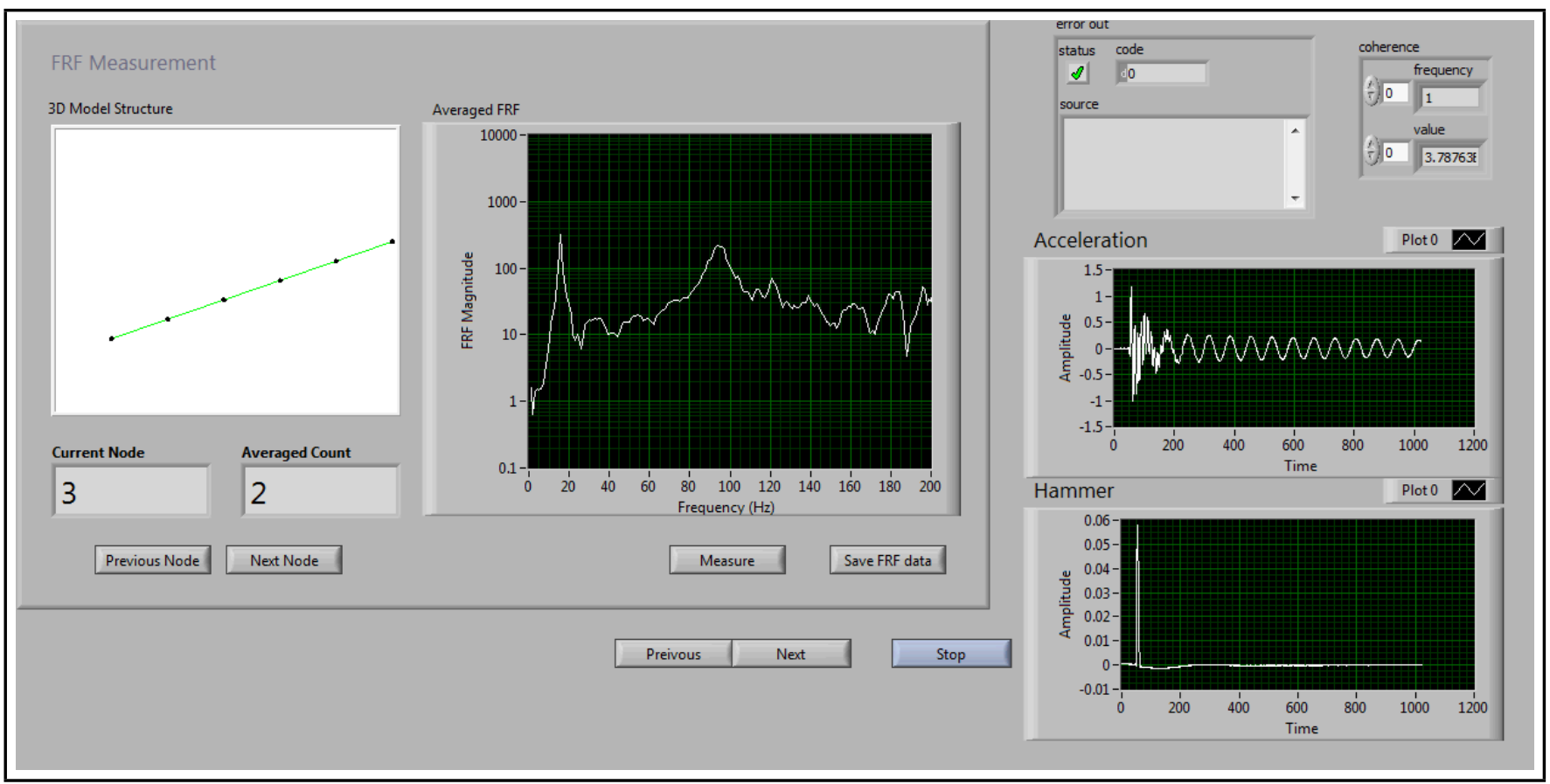

Figure 5. FRF output screen.

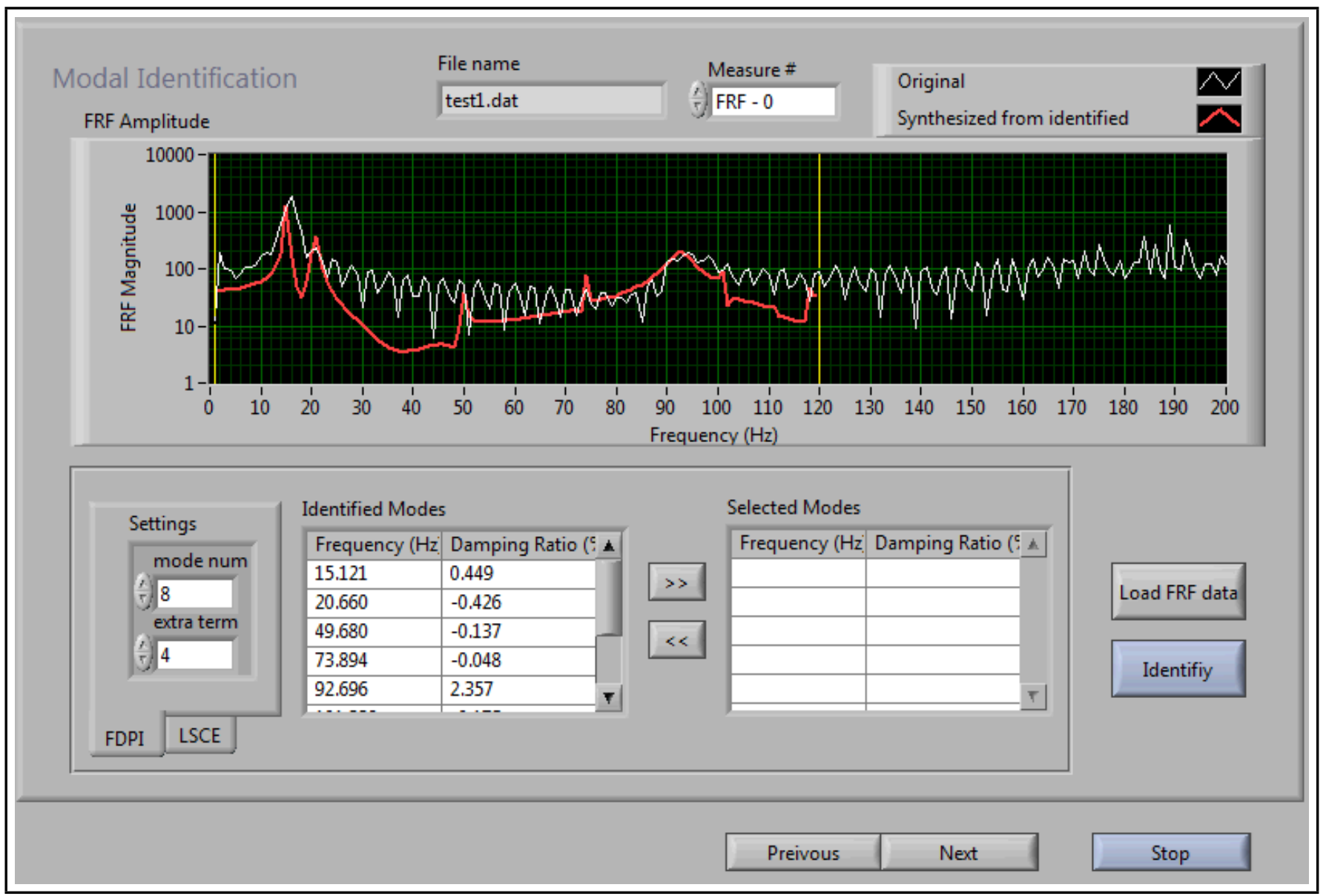

Figure 6. Natural frequencies. 


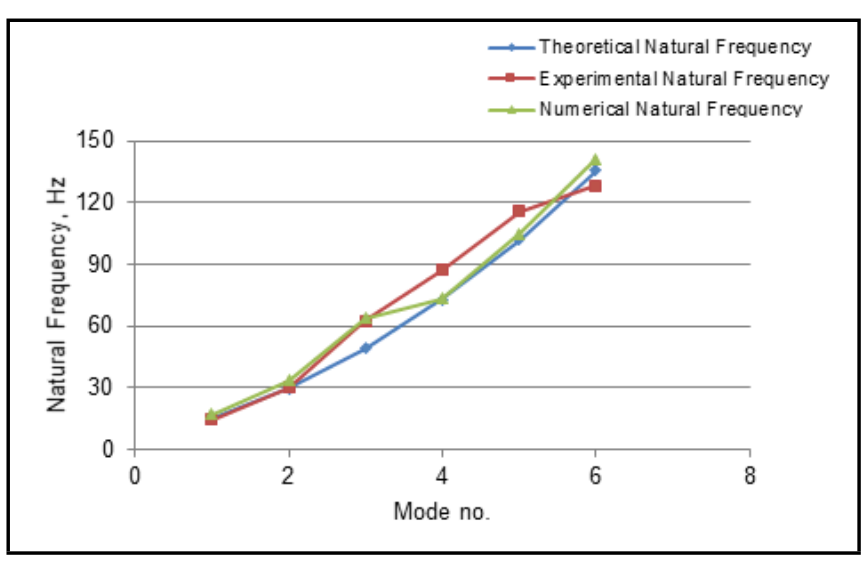

Figure 7. Theoretical and experimental natural frequency of aluminium beam.

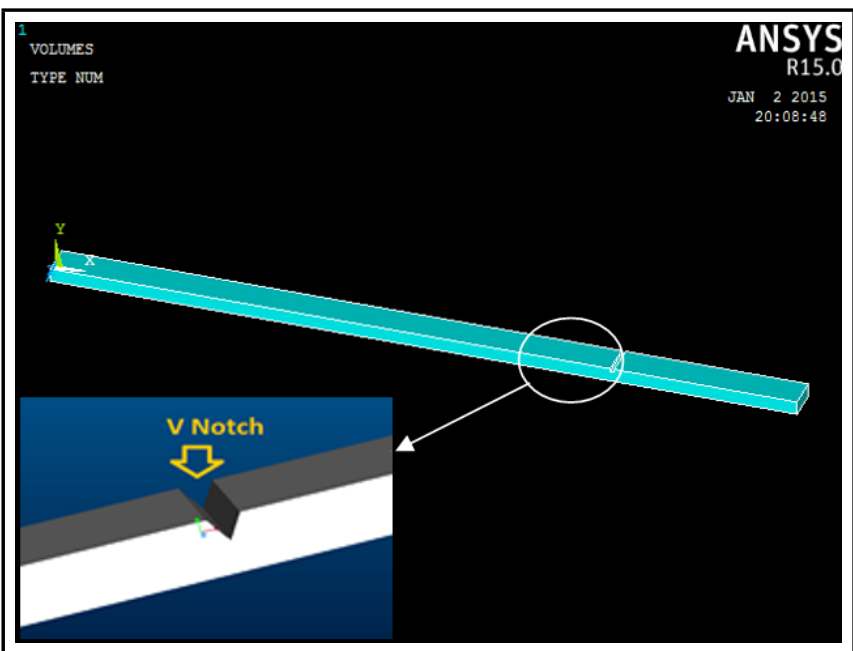

(a)

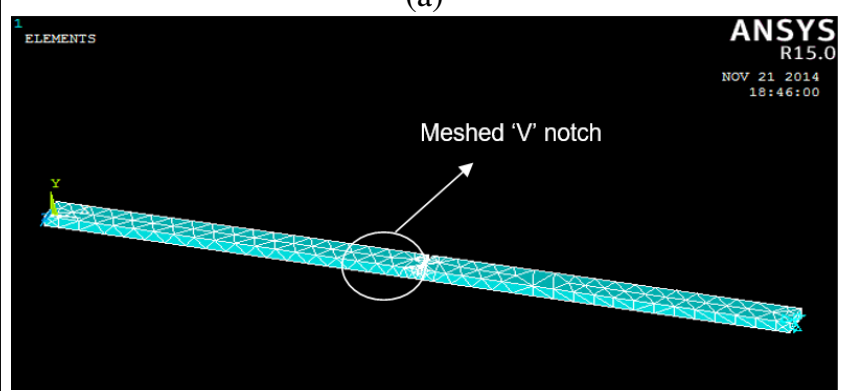

(b)

Figure 8. Cantilever beam with ' $\mathrm{V}$ ' notch (a) Solid model with notch at $137.5 \mathrm{~mm}$ from free end. (b) Meshed model with notch at $275 \mathrm{~mm}$ from free end.

Table 5. Experimental natural frequencies for three modes without notch and with notch.

\begin{tabular}{|c|c|c|c|}
\hline \multirow{2}{*}{$\begin{array}{c}\text { Mode } \\
\text { no. }\end{array}$} & \multirow{2}{*}{$\begin{array}{c}\text { Natural frequency } \\
\text { without notch } \\
(\mathrm{Hz})\end{array}$} & \multicolumn{2}{|c|}{ Natural frequency with notch $(\mathrm{Hz})$} \\
\hline & & $\begin{array}{c}\text { Natural frequency } \\
\text { at } 137.5 \mathrm{~mm}\end{array}$ & $\begin{array}{c}\text { Natural frequency at the } \\
\text { mid-point of beam }\end{array}$ \\
\hline 1 & 35.602 & 26.345 & 26.511 \\
\hline 2 & 61.741 & 56.733 & 60.665 \\
\hline 3 & 117.867 & 116.899 & 117.529 \\
\hline
\end{tabular}

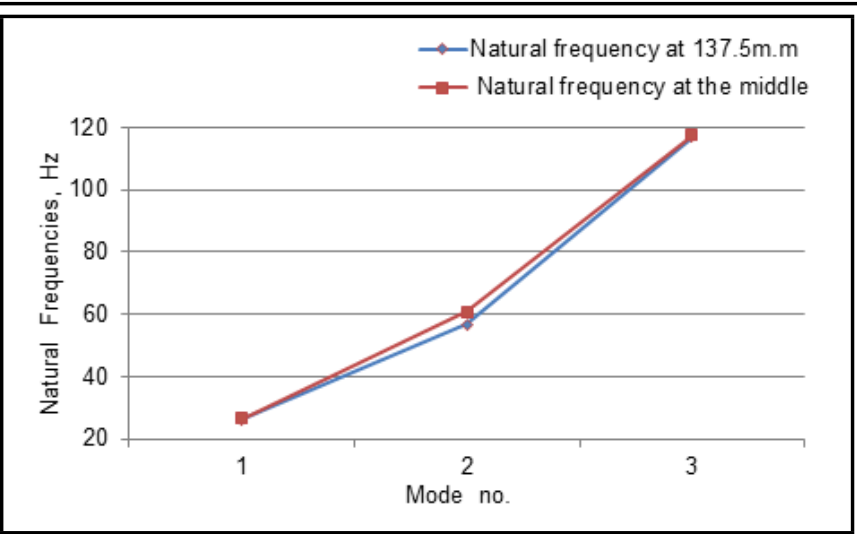

Figure 9. Experimental natural frequencies of three modes with notch.

Table 6. Simulated frequencies of three modes without notch and with notch.

\begin{tabular}{|c|c|c|c|}
\hline $\begin{array}{c}\text { Mode } \\
\text { no. }\end{array}$ & $\begin{array}{c}\text { Natural frequency } \\
\text { Without notch } \\
(\mathrm{Hz})\end{array}$ & $\begin{array}{c}\text { Natural frequency with notch }(\mathrm{Hz}) \\
\text { atural frequency } \\
\text { at } 137.5 \mathrm{~mm}\end{array}$ & $\begin{array}{c}\text { Natural frequency } \\
\text { at the middle }\end{array}$ \\
\hline 1 & 36.84 & 36.515 & 36.824 \\
\hline 2 & 70.711 & 70.209 & 70.219 \\
\hline 3 & 113.97 & 113.72 & 113.82 \\
\hline
\end{tabular}

Table 5 shows the values of experimentally obtained frequencies for three modes of vibration without and with notch at a distance $137.5 \mathrm{~mm}$ and $275 \mathrm{~mm}$ from the free end. From Fig. 9, it is seen that the natural frequency of vibrations decreases for three modes due to stiffness of beam. This effect is due to the influence of notch on beam natural frequency which results in decrease in stiffness of the beam. From this it is observed that the natural frequency has strong dependence upon presence of notch and stiffness. Secondly from Fig. 5 it is observed that there is significant decrease in natural frequency of vibrations when notch is at $137.5 \mathrm{~mm}$ from free end along the length of beam as compared to the mid-point along the length.

Table 6 shows frequencies for three modes without notch and with notch at a distance $137.5 \mathrm{~mm}$ and $275 \mathrm{~mm}$ from free end of beam obtained numerically by using Ansys software. Figure 10 shows numerically determined frequencies of three modes with notch at a distance $137.5 \mathrm{~mm}$ and $275 \mathrm{~mm}$ from free end. From Fig. 10, it is seen that the decrease in natural frequency of vibration is comparatively significant at notch that is at $137.5 \mathrm{~mm}$ from free end as compared to notch at the mid-point of beam.

\section{CONCLUSIONS}

The primary objective of this work was to get insight into how transverse vibrations in cantilever beam due to variations in position of notch affect the natural frequency for different mode numbers. This objective was achieved with the help of extensive analytical work, computer-aided simulation tools, commercially available software, and experimental investigations. From the numerical and experimental investigations, it is seen that natural frequency of vibrating structure is susceptible to change under the influence of notch and its position. The natural frequencies of the vibrating beam changes significantly 


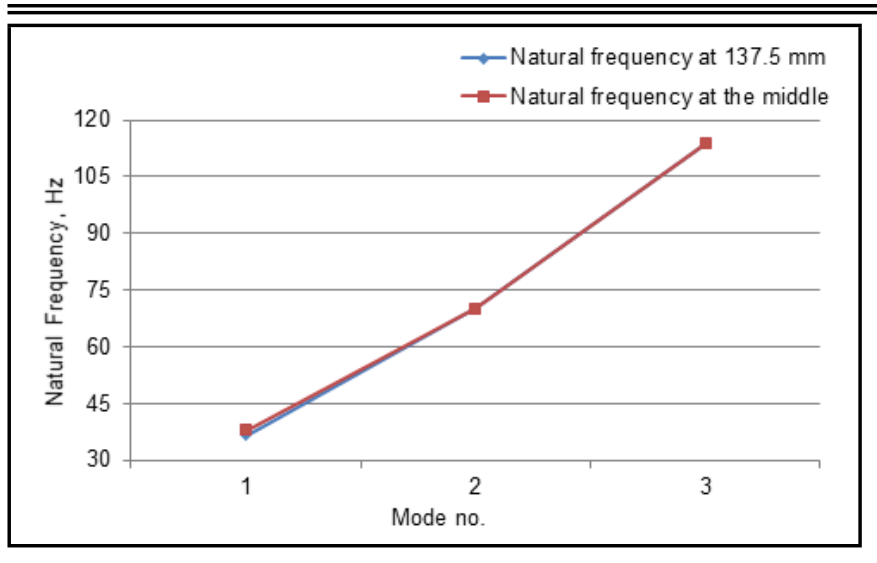

Figure 10. Simulated frequencies of three modes with notch at a distance $137.5 \mathrm{~mm}$ and $275 \mathrm{~mm}$ from free end.

in the presence of notch. There is decrease in natural frequency of cantilever beam due to the effect of notch. From the numerical and experimental investigations, it is seen that the natural frequency of vibration increases by $7 \%$ to $9 \%$ in presence of notch at midpoint when position changes from $137.5 \mathrm{~mm}$ to mid-point of beam.

\section{REFERENCES}

1 Guillaume, P., Modal Analysis, Technical Report, Vrije Universiteit Brussel, Belgium, 1-14, Available: http: //mech.vub.ac.be/avrg/ (2007).

2 Sethi, R., Senapati S. K., and Parhi, D.R.K., Analysis of Crack in Structures Using Finite Element Method, Proceedings of Global Engineering, Science and Technology Conference, (2013).

3 Owolabi, G.M., Swamidas, A.S.J., and Seshadri, R., Crack detection in beams using changes in frequencies and amplitudes of frequency response functions, Journal of Sound and Vibration, 265 (1), 22, (2003).

4 Agarwalla D.K., and Parhi, D.R., Effect of Crack on Modal Parameters of a Cantilever Beam Subjected to Vibration, Procedia Engineering, 51, 665-669, (2013).

5 Nahv, H., and Jabbari, M., Crack detection in beams using experimental modal data and finite element model, 47 (10), 1477-1497, (2005).

6 Georgiades, F., Warminski, J., and Cartmell, M.P., Linear modal analysis of L-shaped beam structures, Mechanical Systems and Signal Processing, 38 (2), 312-332, (2013).

7 Huang L., and Zhang, C., Modal analysis of cantilever plate flutter, Journal of Fluids and Structures, 38 (2), 273-289, (2013).

8 Jassim, Z.A., Ali, N.N., Mustapha, F., and Abdul Jalil N.A., A review on the vibration analysis for a damage occurrence of a cantilever beam, Engineering Failure Analysis, 31, 442-461, (2013).
9 Nguyen, K.V., Mode shapes analysis of a cracked beam and its application for crack detection, Journal of Sound and Vibration, 333 (3), 848-872, (2014).

10 Khiem N.T., and Toan, L.K., A novel method for crack detection in beam-like structures by measurements of natural frequencies, Journal of Sound and Vibration, 333 (18), 4084-4103, (2014).

11 Thalapil, J. and Maiti, S.K., Detection of longitudinal cracks in long and short beams using changes in natural frequencies, International Journal of Mechanical Sciences, 83 38-47, (2014).

12 Nejad, F.B., Khorram, A., and Rezaeian, M., Analytical estimation of natural frequencies and mode shapes of a beam having two cracks, International Journal of Mechanical Sciences, 78, 193-202, (2014).

13 Singh S.K., and Tiwari, R. Detection and localisation of multiple cracks in a shaft system an experimental investigation, Measurement, 53, 182-193, (2014).

14 Jena, P.K., Thatoi, D.N., Nanda, J., and Parhi, D.R.K., Effect of damage parameters on vibration signatures of a cantilever beam, Procedia Engineering, 38, 3318-3330, (2012).

15 Barad, K.H., Sharma, D.S., and Vyas, V. Crack detection in cantilever beam by frequency based method, Procedia Engineering, 51, 770-775, (2013).

16 Sutar, M.K., Finite element analysis of cracked cantilever beam, International Journal of Advanced Engineering Research and Studies, 1 (2), 285-289, (2012).

17 Prasad, R.S. Roy, S.C. and Tyagi, K.P., Effect of Crack Position along Vibrating Cantilever Beam on Crack Growth Rate, International Journal of Engineering Science and Technology, 2, 837-839, (2010).

18 Saavedra, P.N., and Cuitino, L.A., Crack detection and vibration behavior of cracked beam, Computer and Structures, 79 (16), 1451-1459, (2001).

19 Vigneshwaran, K. and Behera, R.K., Vibration Analysis of a Simply Supported Beam with Multiple Breathing Cracks, Procedia Engineering, 86, 835-842, (2014).

20 Sasmal, S., and Ramanjaneyulu, K., Detection and Quantification of Structural Damage of a Beam-Like Structure Using Natural Frequencies, Engineering, 1 (3), 167-176, (2009).

21 Dawari V. B., and Vesmawala, G. R., Structural Damage Identification Using Modal Curvature Differences, IOSR Journal of Mechanical and Civil Engineering, 4, 33-38. 